\title{
Intraoperative Fluid Excess Is a Risk Factor for Pancreatic Fistula after Partial Pancreaticoduodenectomy
}

\author{
Helge Bruns, Veronika Kortendieck, Hans-Rudolf Raab, and Dalibor Antolovic \\ Department of General and Visceral Surgery, Carl von Ossietzky University of Oldenburg, Oldenburg, Germany \\ Correspondence should be addressed to Helge Bruns; helge.bruns@uni-oldenburg.de
}

Received 19 April 2016; Accepted 28 August 2016

Academic Editor: Laureano Fernández-Cruz

Copyright ( 2016 Helge Bruns et al. This is an open access article distributed under the Creative Commons Attribution License, which permits unrestricted use, distribution, and reproduction in any medium, provided the original work is properly cited.

\begin{abstract}
Background. After pancreaticoduodenectomy (PD), pancreatic fistulas (PF) are a frequent complication. Infusions may compromise anastomotic integrity. This retrospective analysis evaluated associations between intraoperative fluid excess and PF. Methods. Data on perioperative parameters including age, sex, laboratory findings, histology, infusions, surgery time, and occurrence of grade B/C PF was collected from all PD with pancreaticojejunostomy (PJ) performed in our department from 12/2011 till 02/2015. The glomerular filtration rate (GFR), infusion rate, and the ratio of both and its association with PF were calculated. ROC analysis was employed to identify a threshold. Results. Complete datasets were available for 83 of 86 consecutive cases. Median age was 66 years (34-84; 60\% male), GFR was $93 \mathrm{~mL} / \mathrm{min}$ (IQR 78-113), and surgery time was $259 \mathrm{~min}$ (IQR 217-307). Intraoperatively, $13.6 \mathrm{~mL} / \mathrm{min}$ (7-31) was infused. In total, $n=18$ (21\%) PF occurred. When the infusion: GFR ratio exceeded 0.15 , PF increased from $11 \%$ to $34 \%$ $(p=0.0157)$. No significant association was detected for any of the other parameters. Conclusions. This analysis demonstrates for the first time an association between intraoperative fluid excess and PF after PD with PJ even in patients with normal renal function. A carefully patient-adopted fluid management with due regard to renal function may help to prevent postoperative PF.
\end{abstract}

\section{Introduction}

In high volume centers, partial pancreaticoduodenectomy (PD) can be performed with acceptable morbidity and mortality [1]. While the outcome is clearly associated with surgeon and center experience, the rate of pancreatic fistulas seems not to drop below a certain level $[2,3]$. Even after thousands of PD, highly experienced surgeons in highvolume centers report an almost constant or even increasing rate of pancreatic fistulas [2]. Depending on the definition, the published rate of postoperative fistulas after PD is estimated to be $20-30 \%$ [4]. Numerous interventions and techniques have been introduced and a number of standardized anastomotic techniques exist, but there is little evidence for superiority of one anastomotic technique over the other [5-13]. Isolation of the pancreaticojejunostomy (PJ) using dual-loop reconstruction has been discussed as possible intervention to decrease the rate of pancreatic fistulas but seems not to be superior to single-loop reconstruction [1].

In multivariate analyses, some risk factors for anastomotic leakage have already been identified [14-18]. Soft pancreatic texture, a history of weight loss, intraoperative blood loss, diameter of the pancreatic duct, and decreased preoperative albumin seem to be associated with leakage. Renal insufficiency has been shown to be associated with increased complication rates after pancreatic resection [19].

In general, intraoperative fluid management aims at stabilizing the patient. For some types of abdominal surgery, a restrictive fluid regimen is considered common sense: as far as liver resection is concerned, fluid management at a low central venous pressure below $5 \mathrm{~cm} \mathrm{H}_{2} \mathrm{O}$ is made use of to decrease intraoperative blood loss [20-23]. Anesthesiological guidelines may vary between institutions but usually consider hemodynamic parameters, blood values, blood loss, and duration of surgery to be triggers that guide the intraoperative regimen [24]. Interstitial fluid overload due to infusion of large amounts of fluid can lead to visible edema and might compromise the anastomotic integrity [25]. For rectal resections, an increased risk of anastomotic leakage after excessive perioperative infusions has been shown [26]. In pancreatic surgery, there is evidence pointing out that the same mechanisms might be relevant. In a study focusing 
on normovolemic hemodilution to decrease blood loss in pancreatic surgery, no effect on blood loss was identified but an increased rate of $21.5 \%$ versus $7.7 \%$ anastomotic complications was apparent after $6250 \mathrm{~mL}$ versus $3900 \mathrm{~mL}$ of intraoperative intravenous fluid [27]. As far as postoperative fluid management is concerned, a restrictive management aiming at a fluid balance of less than 1 liter on postoperative day has been shown to be associated with decreased complication rates [28].

This study was designed to identify associations between renal function, intraoperative infusions, and occurrence of clinical relevant postoperative pancreatic fistulas after PD with PJ.

\section{Methods}

2.1. Patient Data. Data extraction, handling, and analysis were performed in accordance with national and institutional guidelines. All PDs with PJ performed from 12/2011 till $02 / 2015$ were analyzed and data on patient age, indication to surgery, concomitant diseases, preoperative laboratory values, duration of surgery, blood loss, intraoperative infusions, postoperative infusions during the first 72 hours after surgery, occurrence of pancreatic fistulas, and interventions (both surgical or other) was extracted from patient folders. Glomerular filtration rate (GFR) was calculated as published elsewhere [29]. Patients with pancreaticogastrostomies were excluded. PF were considered to be clinically relevant when drainages had to be kept longer than $72 \mathrm{~h}$ and pancreatic enzyme levels in the drainage fluid were at least three times higher than in the serum, drainages had to be reintroduced (e.g., guided using computer tomography or ultrasound), and pancreatic enzymes were detected in the drainage fluid or patients had to undergo reoperations for complications caused by PF.

While duct diameter and pancreatic texture have been discussed as factors associated with postoperative fistula, these parameters lack clear definitions: "duct wideness" and "tissue softness" strongly depend on the individual surgeon's definition and experience. Without clear definition of both parameters prior to documentation, including this type of data in a retrospective analysis cannot be considered to be reliable. Thus, we did not include this in our analysis and have assumed an equal distribution of both parameters between groups.

2.2. Statistical Analysis. For descriptive statistics, median and interquartile range (IQR) or range are used unless stated otherwise. To determine a meaningful cutoff for the infusion rate:GFR ratio, receiver operating characteristics (ROC) were employed, and the area under the ROC curve (AUCROC) and Youden's $J$ were calculated. Testing for statistical significance was performed using ANOVA and Fisher's Exact Test as appropriate. $p$ values were two tailed and a value of $p<0.05$ was considered statistically significant.

2.3. Surgical Technique and Postoperative Management. In our institution, PD is performed in a highly standardized fashion. Usually, single-loop reconstruction with a WarrenCattell end-to-side PJ using poly-p-dioxanone (PDS 5.0, Johnson \& Johnson Medical GmbH, Ethicon, Norderstedt, Germany) is performed. A pancreaticogastrostomy may be performed depending on the surgeon's choice. A surgical drain is routinely placed to the pancreatic anastomosis. Intraoperative and postoperative fluid management and postoperative course are routinely monitored and logged. Patients are extubated in the operating room and transferred to the intensive care unit where mobilization is started and oral fluids are introduced on the day of surgery. Solid foods are introduced depending on enteral passage. As soon as patients have been stable for at least 24 hours, they are transferred to the intermediate care ward. Drains are removed as soon as the fluid is less than $500 \mathrm{~mL}$ and is serous. If there is suspicion of a PF, drains are kept in place and enzyme levels are monitored in the drainage fluid.

\section{Results}

In total, 83 complete datasets were available from 86 consecutive PD with PJ. In total, $n=18$ (21\%) relevant pancreatic fistulas occurred (Table 1). Median age was 66 years (range 34-84 years; $60 \%$ male), GFR was $93 \mathrm{~mL} / \mathrm{min}$ (IQR 78$113 \mathrm{~mL} / \mathrm{min}$; Figure 1), and surgery time was $259 \mathrm{~min}$ (IQR 217-307; Table 1). Intraoperatively, $13.6 \mathrm{~mL} / \mathrm{min}$ (range 7$31 \mathrm{~mL} / \mathrm{min}$ ) was infused (Figure 2; Table 1). Crystalloids were used in all patients during surgery and during the first $72 \mathrm{~h}$ after surgery. Colloids were infused in $46 \%$ of patients during surgery (56\% and $43 \%$ in patients with and without fistulas; $p=0.4264$ ), while $24 \%$ of patients received colloids during the first $72 \mathrm{~h}$ after surgery ( $0 \%$ versus $31 \%$ in patients with and without fistulas; $p=0.0046$; Table 1 ). The amount of postoperative infusions had no effect on occurrence of pancreatic fistulas (Table 1). Except for creatinine, GFR, and postoperative infusion of colloids, no statistical differences were identified between patients with or without pancreatic fistulas (Table 1). There was no correlation between the amount of intraoperatively infused volume and GFR (Figure 3). ROC analysis identified an infusion rate: GFR ratio of 0.15 as threshold for occurrence of pancreatic fistulas (Figure 4). A significant increase of pancreatic fistulas from $11 \%$ to $34 \%$ was detected for patients below and above the identified threshold ( $p=0.0157$; Table 2 ).

\section{Discussion}

Perioperative fluid management strongly depends on teamwork involving both anesthesiologists and surgeons [30]. This can be quite demanding and needs experience on the anesthesiologists' side similar to surgical experience needed when complex surgery is performed. Without a balanced and careful fluid regimen, the surgery's success is jeopardized. It is a common misconception that fluid management has little effect on surgical complication rates, although this has been demonstrated frequently [22, 23, 26$28,31]$. In abdominal surgery, restrictive fluid management has repeatedly proven to be superior over dilutive regimens. 
TABLE 1: Patient characteristics.

\begin{tabular}{|c|c|c|c|c|c|}
\hline & \multicolumn{2}{|c|}{ Postop. fistula $(n=18)$} & \multicolumn{2}{|c|}{ No postop. fistula $(n=65)$} & \multirow{2}{*}{$p$} \\
\hline & $n$ & $\%$ & $n$ & $\%$ & \\
\hline Sex & & & & & 0.5956 \\
\hline Female & 6 & 33 & 27 & 42 & \\
\hline \multirow[t]{2}{*}{ Male } & 12 & 67 & 38 & 58 & \\
\hline & \multicolumn{2}{|c|}{ Median (IQR) } & \multicolumn{2}{|c|}{ Median (IQR) } & \\
\hline Age [years] & \multicolumn{2}{|c|}{$65(58.25-73)$} & \multicolumn{2}{|c|}{$66(57-73)$} & 0.8038 \\
\hline Creatinine $[\mathrm{mg} / \mathrm{dL}]$ & \multicolumn{2}{|c|}{$0.9(0.725-1.0)$} & \multicolumn{2}{|c|}{$0.8(0.7-0.9)$} & 0.0074 \\
\hline GFR $[\mathrm{mL} / \mathrm{min}]$ & \multicolumn{2}{|c|}{$83(61-98)$} & \multicolumn{2}{|c|}{$100(79-115)$} & 0.0219 \\
\hline Surgical duration [min] & \multicolumn{2}{|c|}{$231(202-295)$} & \multicolumn{2}{|c|}{$230(262-313)$} & 0.5004 \\
\hline \multicolumn{6}{|l|}{ Intraoperative infusions } \\
\hline Total $[\mathrm{mL}]$ & \multicolumn{2}{|c|}{$3250(3000-4188)$} & \multicolumn{2}{|c|}{$3500(3000-4000)$} & 0.5626 \\
\hline Infusion rate $[\mathrm{mL} / \mathrm{min}]$ & \multicolumn{2}{|c|}{$13.4(10.7-17.0)$} & \multicolumn{2}{|c|}{$13.8(10.8-16.1)$} & 0.9634 \\
\hline INF : GFR & \multicolumn{2}{|c|}{$0.1688(0.1397-0.2403)$} & \multicolumn{2}{|c|}{$0.1465(0.1043-0.1743)$} & 0.0585 \\
\hline \multirow[t]{2}{*}{ Postop. infusions [mL/72 h] } & \multicolumn{2}{|c|}{12763 (11778.25-14718.75) } & \multicolumn{2}{|c|}{$12500(11548.75-14157.5)$} & 0.8501 \\
\hline & $n$ & $\%$ & $n$ & $\%$ & \\
\hline \multicolumn{6}{|l|}{ Usage of colloids } \\
\hline Intraoperatively & 10 & 56 & 28 & 43 & 0.4264 \\
\hline Postoperatively & 0 & 0 & 20 & 31 & 0.0046 \\
\hline
\end{tabular}

IQR: interquartile range; GFR: glomerular filtration rate; INF : GFR: infusion rate [mL/min] : GFR [mL/min] ratio.

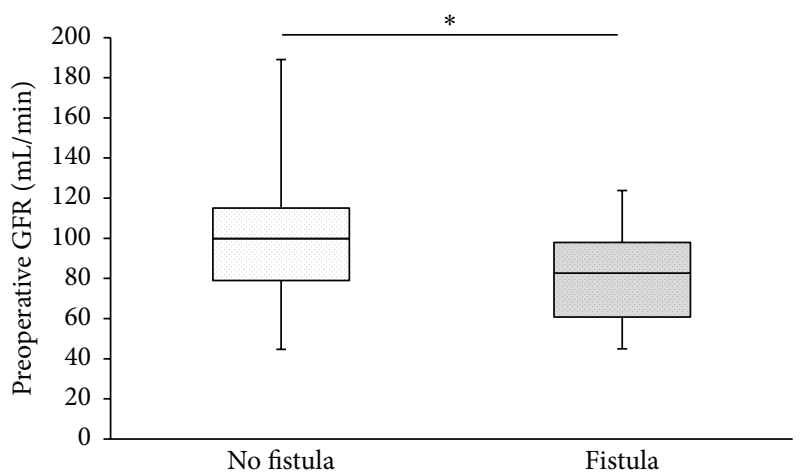

FIGURE 1: Glomerular filtration rate (GFR). In patients with postoperative pancreatic fistulas, the median GFR was $83 \mathrm{~mL} / \mathrm{min}$ versus $100 \mathrm{~mL} / \mathrm{min}$ in patients without fistulas $\left({ }^{*} p=0.0219\right)$.

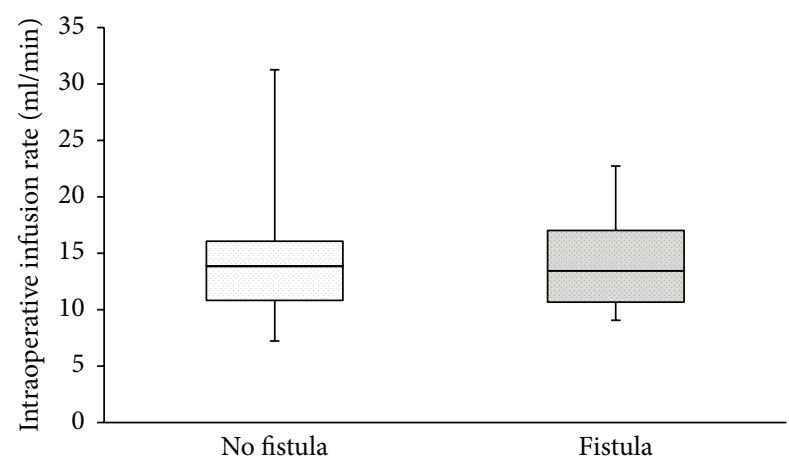

FIGURE 2: Intraoperative infusion rates $(\mathrm{mL} / \mathrm{min})$. No significant difference was detected for intraoperative infusions for patients with versus without postoperative pancreatic fistulas $(p=0.9633)$.

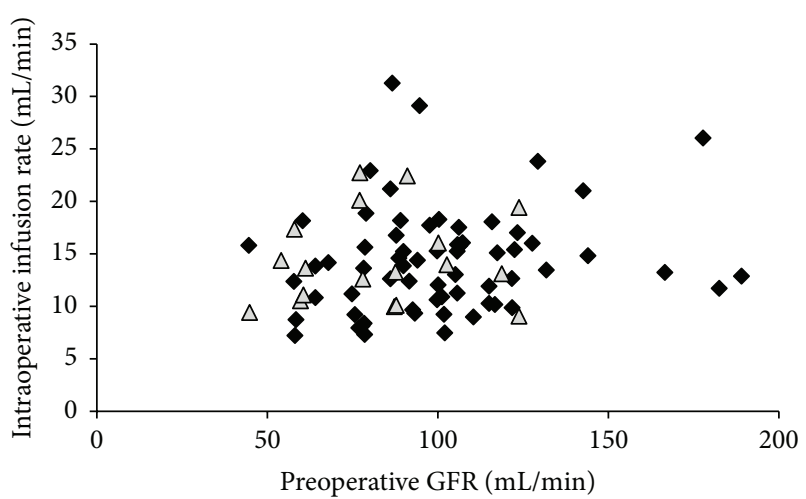

FIGURE 3: Scatterplot illustrating correlation between GFR and intraoperative infusion rate. Intraoperative infusion rates were not related to preoperative GFR (coefficient of determination: $r^{2}=$ 0.0271). Black squares: patients without fistulas. Grey triangles: patients with fistulas.

In liver resection, restrictive fluid management is used to achieve a low central venous pressure and leads to decreased intraoperative blood loss, which is known to be associated with increased morbidity $[22,23]$. In rectum resection, anastomotic complications increase after perioperative fluid excess [26]. In pancreatic surgery, both intraoperative and postoperative amounts of infusions have been linked to anastomotic complications [27, 28]. Excessive (and in this context: mindless) infusion management can be linked to increased postoperative complications including impaired wound healing, pulmonary complications, and intestinal paralysis [31-35]. It seems obvious that successful fluid 


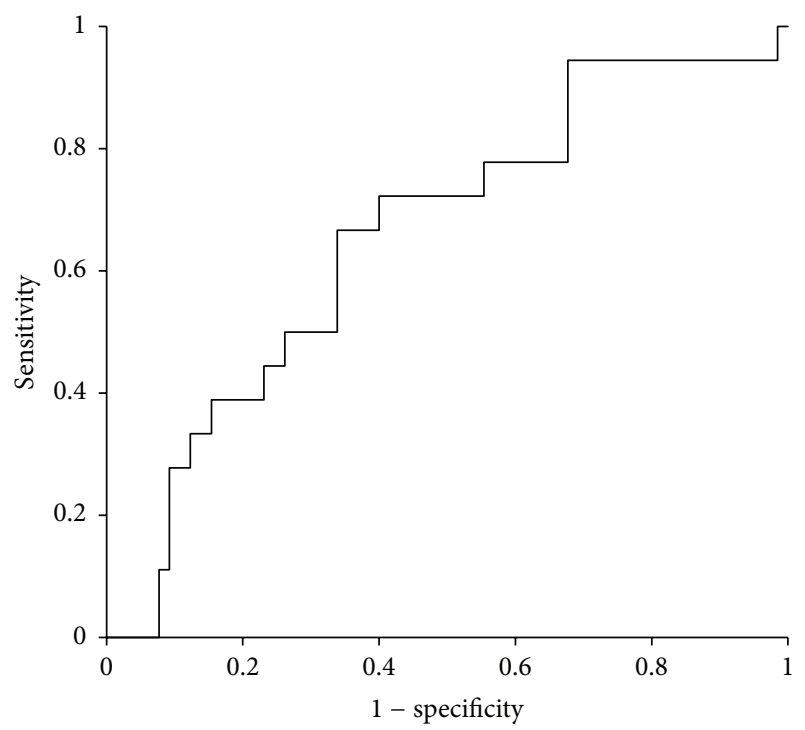

FIGURE 4: Receiver operating characteristics (ROC) curve for the infusion rate : GFR ratio. A threshold of 0.15 was detected using ROC analysis (ROC-AUC: 0.6564; Youden's $J$ for 0.15: 0.3282).

management in pancreatic surgery needs to be balanced: while excretory renal function can visually be monitored during surgery and hemodynamic parameters are constantly made use of as triggers for infusions and pharmacological interventions, renal function is usually only considered important when already compromised. Most of our patients had a normal renal function with a GFR within normal values (Table 1, Figure 1). Nonetheless, it is quite clear that even the hardest working and healthiest kidney can be overloaded by volume excess. Interstitial fluid shifting can result from generous substitution during surgery and is aggravated by increased vascular permeability [30]. In these cases, resulting edema is visible for surgeons and should be considered an alarm signal and threat to the patient, especially when risky anastomoses with known potential of fistulas need to be carried out. In the authors' opinion, this mechanism, which is supported by the findings presented in this study, seems intuitive and quite obvious. Consequently, anesthesiologists need to hand over part of the responsibility for adequate fluid management to surgeons and need to be aware that misguided fluid management can increase risk of surgical complications. The bottom line is that there is a good share of responsibility for surgical complications for the anesthesiologist and every discipline involved in the teamwork necessary to carry out complex surgical procedures needs to understand any intraoperative action contributes to success or failure.

Perioperative infusion management relies on both measurable parameters and experience. Fluid overload needs to be avoided, while fluids lost need to be replaced and hemodynamic parameters need to be manipulated to stabilize the patient during and after surgery [30]. During induction of anesthesia, a starting bolus volume is very often applied and is considered necessary to compensate for both hypovolemia of the fasting patient and vasodilatation during anesthesia
TABLE 2: Rates of postoperative pancreatic fistulas for patients exceeding the infusion rate: GFR ratio.

\begin{tabular}{lcccc}
\hline & \multicolumn{2}{c}{ INF : GFR $\geq 0.15$} & \multicolumn{2}{c}{ INF : GFR $<0.15$} \\
& $n=38$ & $100 \%$ & $n=45$ & $100 \%$ \\
\hline Postoperative fistula & 13 & 34 & 5 & 11 \\
No postoperative fistula & 25 & 66 & 40 & 89 \\
\hline
\end{tabular}

INF : GFR: infusion rate $[\mathrm{mL} / \mathrm{min}]$ : glomerular filtration rate $[\mathrm{mL} / \mathrm{min}]$ ratio. $p=0.0157$.

or caused by epidural catheters [36-38]. This has been considered good practice for years but may be inappropriate and the foundation to postoperative complications even before surgery starts. During surgery, excessive volumes are infused to compensate loss to the third space, which has been an accepted concept for decades but may not even exist $[39,40]$. Very often, sympathomimetic medication will be avoided since an impaired renal function is feared and crystalloids and colloids will be applied [41]. Intraoperatively, no significant difference was seen for the type of infusion solutions (i.e., crystalloids versus colloids) in our patients. Most interestingly, there was a striking difference in postoperative regimens: none of the patients with fistulas had received colloids during the first $72 \mathrm{~h}$ after surgery. Smaller volumes of colloids are needed to achieve the same effect compared to crystalloids; thus crystalloid substitution using colloids might be a worthwhile intervention, but data on this topic remains controversial [42]. It has to be remarked that in large meta-analyses no positive effect on survival and complications rates of colloids versus crystalloids could be identified; consequently, the usage of colloids has decreased over the last decade while the rate of pancreatic fistulas after $\mathrm{PD}$ with PJ remained unchanged $[2,43]$.

In a study from 2014, a threshold of $1 \mathrm{~L}$ positive fluid balance on postoperative day one was identified to be associated with an increased risk of complications after pancreatic surgery [28]. Since fluid balance during the first $24 \mathrm{~h}$ after surgery exceeded $1 \mathrm{~L}$ in any of our patients, this finding was not reproducible using our data.

\section{Conclusion}

Pancreatic surgery involves both sophisticated surgical and anesthesiological management, amongst other prerequisites [44-46]. Fluid management, which is within reach for interventions, needs to be considered as surgical and anesthesiological teamwork [30,47]. Our analysis has demonstrated a clear association between intraoperative fluid excess and occurrence of pancreatic fistulas after PD with PJ even in patients with normal renal function. When in our patients the intraoperative infusion rate: GFR ratio exceeded 0.15 , the rate of postoperative pancreatic fistulas was more than tripled. Our analysis points at an increased use of intra- and postoperative colloids as a possible intervention. High quality randomized clinical trials comparing different fluid regimens are needed to generate evidence in this important aspect of pancreatic surgery. 


\section{Competing Interests}

The authors declare that they have no competing interests.

\section{References}

[1] U. Klaiber, P. Probst, P. Knebel et al., "Meta-analysis of complication rates for single-loop versus dual-loop (Roux-en$\mathrm{Y}$ ) with isolated pancreaticojejunostomy reconstruction after pancreaticoduodenectomy," British Journal of Surgery, vol. 102, pp. 331-340, 2015.

[2] J. L. Cameron and J. He, "Two thousand consecutive pancreaticoduodenectomies," Journal of the American College of Surgeons, vol. 220, no. 4, pp. 530-536, 2015.

[3] U. A. Wittel, F. Makowiec, O. Sick et al., "Retrospective analyses of trends in pancreatic surgery: indications, operative techniques, and postoperative outcome of 1,120 pancreatic resections," World Journal of Surgical Oncology, vol. 13, article 102, 2015.

[4] W. B. Pratt, M. P. Callery, and C. M. Vollmer Jr., "Risk prediction for development of pancreatic fistula using the ISGPF classification scheme," World Journal of Surgery, vol. 32, no. 3, pp. 419428, 2008.

[5] C. G. Ball and T. J. Howard, "Does the type of pancreaticojejunostomy after whipple alter the leak rate?" Advances in Surgery, vol. 44, no. 1, pp. 131-148, 2010.

[6] L. Chen, "Applying transductal invaginational pancreaticojejunostomy to decrease pancreatic leakage after pancreaticoduodenectomy," Hepato-Gastroenterology, vol. 60, no. 125, pp. 10181020, 2013.

[7] Y. Chen, N. Ke, C. Tan et al., "Continuous versus interrupted suture techniques of pancreaticojejunostomy after pancreaticoduodenectomy," Journal of Surgical Research, vol. 193, no. 2, pp. 590-597, 2015.

[8] D. Hashimoto, M. Hirota, Y. Yagi, and H. Baba, "End-toside pancreaticojejunostomy without stitches in the pancreatic stump," Surgery Today, vol. 43, no. 7, pp. 821-824, 2013.

[9] D. D. Karavias, D. D. Karavias, I. G. Chaveles, S. K. Kakkos, N. A. Katsiakis, and I. C. Maroulis, “'True' duct-to-mucosa pancreaticojejunostomy, with secure eversion of the enteric mucosa, in whipple operation," Journal of Gastrointestinal Surgery, vol. 19, no. 3, pp. 498-505, 2015.

[10] T. Keck, U. F. Wellner, M. Bahra et al., "Pancreatogastrostomy versus pancreatojejunostomy for RECOnstruction After PANCreatoduodenectomy (RECOPANC, DRKS 00000767)," Annals of Surgery, vol. 263, no. 3, pp. 440-449, 2015.

[11] A. Kleespies, M. Rentsch, H. Seeliger, M. Albertsmeier, K. W. Jauch, and C. J. Bruns, "Blumgart anastomosis for pancreaticojejunostomy minimizes severe complications after pancreatic head resection," British Journal of Surgery, vol. 96, no. 7, pp. 741750, 2009.

[12] B. Menahem, L. Guittet, A. Mulliri, A. Alves, and J. Lubrano, "Pancreaticogastrostomy is superior to pancreaticojejunostomy for prevention of pancreatic fistula after pancreaticoduodenectomy: an updated meta-analysis of randomized controlled trials," Annals of Surgery, vol. 261, no. 5, pp. 882-887, 2015.

[13] N. Torer, A. Ezer, and T. Z. Nursal, "Mattress sutures for the modification of end-to-end dunking pancreaticojejunostomy," Hepatobiliary and Pancreatic Diseases International, vol. 12, no. 5, pp. 556-558, 2013.

[14] U. F. Wellner, G. Kayser, H. Lapshyn et al., "A simple scoring system based on clinical factors related to pancreatic texture predicts postoperative pancreatic fistula preoperatively," $H P B$, vol. 12, no. 10, pp. 696-702, 2010.

[15] T. Schnelldorfer, P. D. Mauldin, D. N. Lewin, and D. B. Adams, "Distal pancreatectomy for chronic pancreatitis: risk factors for postoperative pancreatic fistula," Journal of Gastrointestinal Surgery, vol. 11, no. 8, pp. 991-997, 2007.

[16] S.-J. Fu, S.-L. Shen, S.-Q. Li et al., "Risk factors and outcomes of postoperative pancreatic fistula after pancreaticoduodenectomy: an audit of 532 consecutive cases," BMC Surgery, vol. 15, article 34, 2015.

[17] Y. Fujiwara, H. Shiba, Y. Shirai et al., "Perioperative serum albumin correlates with postoperative pancreatic fistula after pancreaticoduodenectomy," Anticancer Research, vol. 35, no. 1, pp. 499-504, 2015.

[18] L. Yu, Q. Huang, F. Xie, X. Lin, and C. Liu, "Risk factors of postoperative complications of pancreatoduodenectomy," Hepato-gastroenterology, vol. 61, no. 135, pp. 2091-2095, 2014.

[19] M. H. Squires III, V. V. Mehta, S. B. Fisher et al., "Effect of preoperative renal insufficiency on postoperative outcomes after pancreatic resection: a single institution experience of 1,061 consecutive patients," Journal of the American College of Surgeons, vol. 218, no. 1, pp. 92-101, 2014.

[20] R. M. Jones, C. E. Moulton, and K. J. Hardy, "Central venous pressure and its effect on blood loss during liver resection," British Journal of Surgery, vol. 85, no. 8, pp. 1058-1060, 1998.

[21] Z. Li, Y.-M. Sun, F.-X. Wu, L.-Q. Yang, Z.-J. Lu, and W.-F. $\mathrm{Yu}$, "Controlled low central venous pressure reduces blood loss and transfusion requirements in hepatectomy," World Journal of Gastroenterology, vol. 20, no. 1, pp. 303-309, 2014.

[22] P. Schemmer, H. Bruns, J. Weitz, J. Schmidt, and M. W. Büchler, "Liver transection using vascular stapler: a review," $H P B$, vol. 10, no. 4, pp. 249-252, 2008.

[23] H. Bruns, M. W. Büchler, and P. Schemmer, "Liver transection: modern procedure: technique, results and costs," Chirurg, vol. 86, no. 6, pp. 552-560, 2015.

[24] T. Tatara, Y. Nagao, and C. Tashiro, “The effect of duration of surgery on fluid balance during abdominal surgery: a mathematical model," Anesthesia and Analgesia, vol. 109, no. 1, pp. 211-216, 2009.

[25] D. N. Lobo, D. A. L. Macafee, and S. P. Allison, "How perioperative fluid balance influences postoperative outcomes," Best Practice and Research: Clinical Anaesthesiology, vol. 20, no. 3, pp. 439-455, 2006.

[26] A. K. Boesen, Y. Maeda, and M. Rorbæk Madsen, "Perioperative fluid infusion and its influence on anastomotic leakage after rectal cancer surgery: implications for prevention strategies," Colorectal Disease, vol. 15, no. 9, pp. e522-e527, 2013.

[27] M. Fischer, K. Matsuo, M. Gonen et al., "Relationship between intraoperative fluid administration and perioperative outcome after pancreaticoduodenectomy: results of a prospective randomized trial of acute normovolemic hemodilution compared with standard intraoperative management," Annals of Surgery, vol. 252, no. 6, pp. 952-958, 2010.

[28] L. Weinberg, D. Wong, D. Karalapillai et al., "The impact of fluid intervention on complications and length of hospital stay after pancreaticoduodenectomy (Whipple's procedure)," $B M C$ Anesthesiology, vol. 14, article 35, 2014.

[29] S. Klahr, A. S. Levey, G. J. Beck et al., “The effects of dietary protein restriction and blood-pressure control on the progression of chronic renal disease. Modification of Diet in Renal Disease Study Group," The New England Journal of Medicine, vol. 330, no. 13, pp. 877-884, 1994. 
[30] B. Brandstrup, "Fluid therapy for the surgical patient," Best Practice and Research: Clinical Anaesthesiology, vol. 20, no. 2, pp. 265-283, 2006.

[31] B. Brandstrup, H. Tonnesen, R. Beier-Holgersen et al., "Effects of intravenous fluid restriction on postoperative complications: comparison of two perioperative fluid regimens: a randomized assessor-blinded multicenter trial," Annals of Surgery, vol. 238, pp. 641-648, 2003.

[32] K. Holte, N. E. Sharrock, and H. Kehlet, "Pathophysiology and clinical implications of perioperative fluid excess," British Journal of Anaesthesia, vol. 89, no. 4, pp. 622-632, 2002.

[33] K. Jonsson, J. A. Jensen, W. H. Goodson III et al., "Tissue oxygenation, anemia, and perfusion in relation to wound healing in surgical patients," Annals of Surgery, vol. 214, no. 5, pp. 605-613, 1991.

[34] T. E. Miller, K. Raghunathan, and T. J. Gan, "State-of-the-art fluid management in the operating room," Best Practice and Research: Clinical Anaesthesiology, vol. 28, no. 3, pp. 261-273, 2014.

[35] D. W. Wilmore, R. J. Smith, S. T. O'Dwyer, D. O. Jacobs, T. R. Ziegler, and X.-D. Wang, "The gut: a central organ after surgical stress," Surgery, vol. 104, no. 5, pp. 917-923, 1988.

[36] A. F. McCrae and J. A. W. Wildsmith, "Prevention and treatment of hypotension during central neural block," British Journal of Anaesthesia, vol. 70, no. 6, pp. 672-680, 1993.

[37] A. M. Pouta, J. Karinen, O. J. Vuolteenaho, and T. J. Laatikainen, "Effect of intravenous fluid preload on vasoactive peptide secretion during Caesarean section under spinal anaesthesia," Anaesthesia, vol. 51, no. 2, pp. 128-132, 1996.

[38] G. E. Morgan, M. S. Mikhail, and M. J. Murray, Clinical Anesthesiology, vol. 14, Lange Medical Books/McGraw Hill, New York, NY, USA, 2006.

[39] E. A. M. Frost, "The rise and fall of the third space: appropriate intraoperative fluid management," Journal of the Medical Association of Thailand, vol. 96, no. 8, pp. 1001-1008, 2013.

[40] M. Jacob, D. Chappell, and M. Rehm, "The 'third space'-fact or fiction?" Best Practice and Research: Clinical Anaesthesiology, vol. 23, no. 2, pp. 145-157, 2009.

[41] J. W. Sear, "Kidney dysfunction in the postoperative period," British Journal of Anaesthesia, vol. 95, no. 1, pp. 20-32, 2005.

[42] D. Orbegozo Cortés, T. Gamarano Barros, H. Njimi, and J.-L. Vincent, "Crystalloids versus colloids: exploring differences in fluid requirements by systematic review and meta-regression," Anesthesia \& Analgesia, vol. 120, no. 2, pp. 389-402, 2015.

[43] P. Perel, I. Roberts, and K. Ker, "Colloids versus crystalloids for fluid resuscitation in critically ill patients," Cochrane Database of Systematic Reviews, vol. 2, Article ID CD000567, 2013.

[44] G. Alemanno, C. Bergamini, J. Martellucci et al., "Surgical outcome of pancreaticoduodenectomy: high volume center or multidisciplinary management?" Minerva Chirurgica, vol. 71, no. 1, pp. 8-14, 2016.

[45] F. Gani, Y. Kim, M. J. Weiss et al., "Effect of surgeon and anesthesiologist volume on surgical outcomes," Journal of Surgical Research, vol. 200, no. 2, pp. 427-434, 2016.

[46] H. Bruns, N. N. Rahbari, T. Löffler et al., "Perioperative management in distal pancreatectomy: results of a survey in 23 European participating centres of the DISPACT trial and a review of literature," Trials, vol. 10, article 58, 2009.

[47] K. Raghunathan, M. Singh, and D. N. Lobo, "Fluid management in abdominal surgery. what, when, and when not to administer," Anesthesiology Clinics, vol. 33, no. 1, pp. 51-64, 2015. 


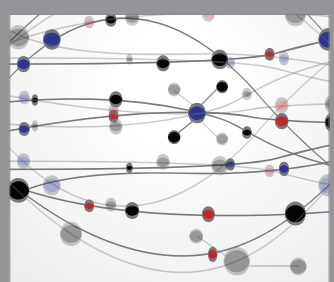

The Scientific World Journal
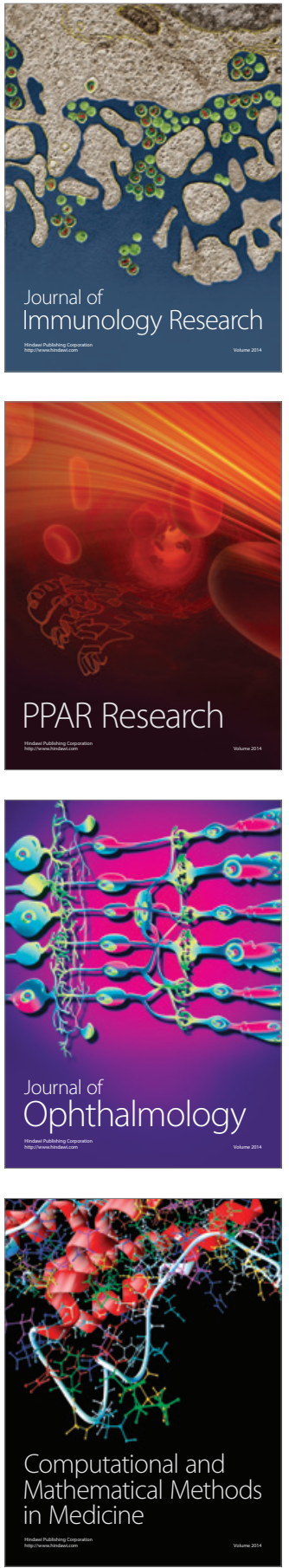

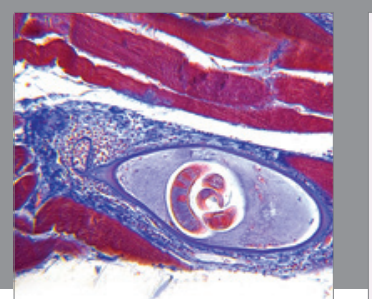

Gastroenterology Research and Practice

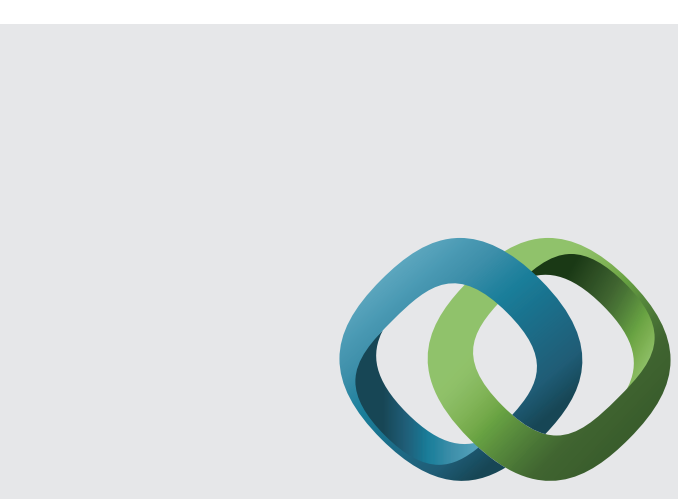

\section{Hindawi}

Submit your manuscripts at

http://www.hindawi.com
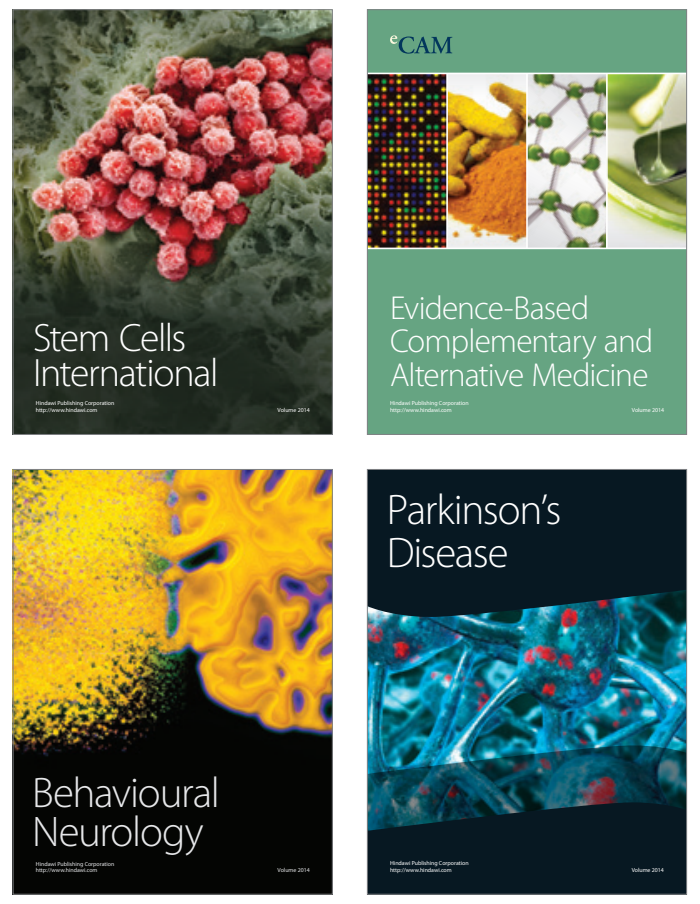
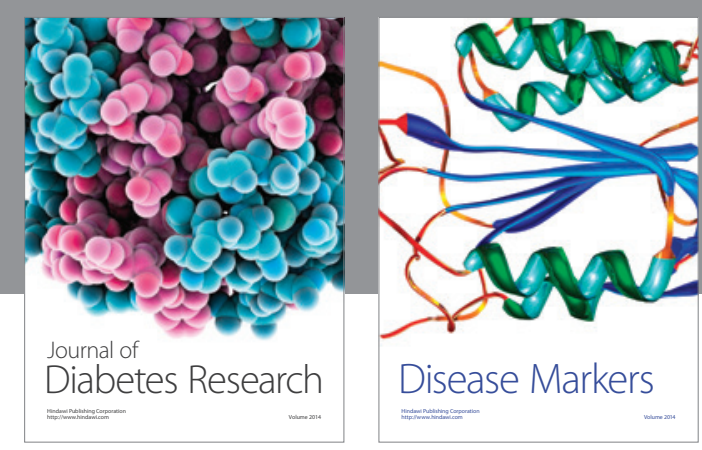

Disease Markers
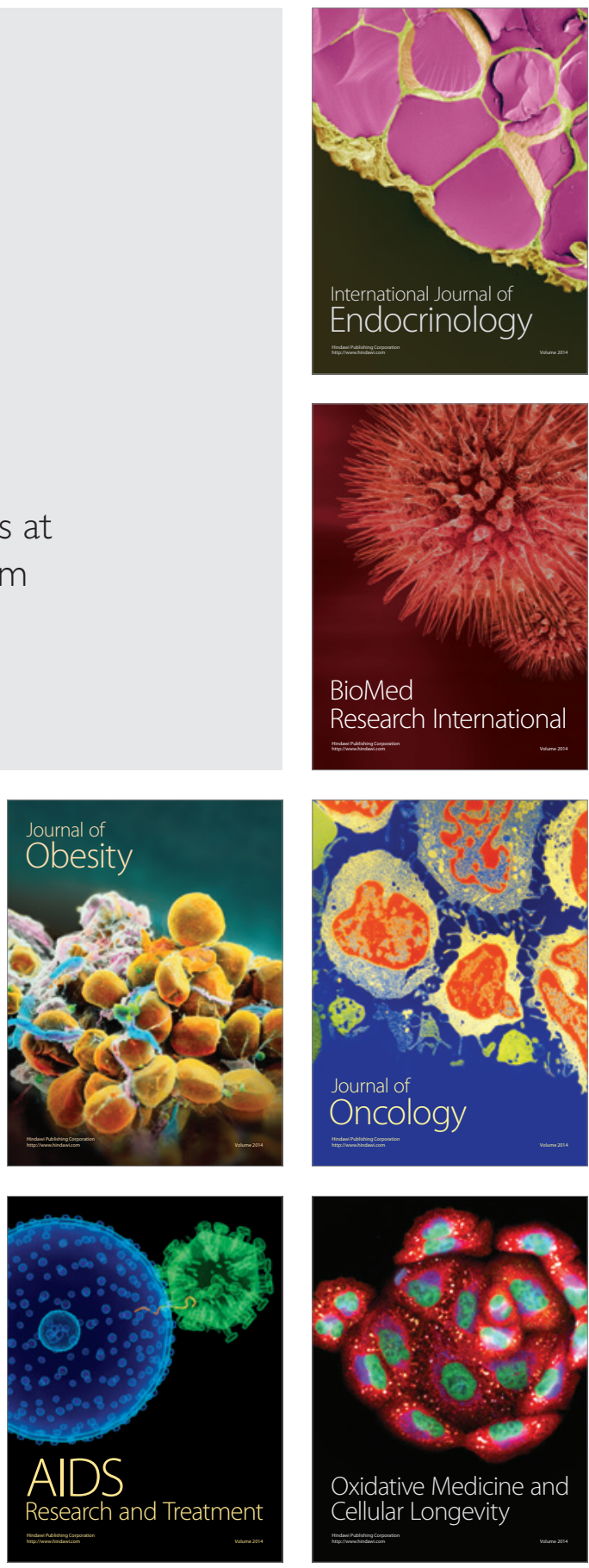